\title{
PHYSICAL PROPERTIES OF NEW EGYPTIAN PADDY RICE VARIETIES
}

\author{
"M. E. Yehia, *A. Ramadan, *T. E. Abou-Zaid and *D. Abdelbary
}

ABSTRACT

Some physical properties of paddy rice are necessary for the drying, parboiling, storage structures, storage, and processing equipment and for the design of handling, transportation and processing operations. The physical properties length (L), width (W), thickness (T) of four Egyptian varieties paddy rice were determined at a moisture content of $14 \% \pm 0.24$ $\%$ (wet basis) namely Egyptian jasmine, Sakha 106, Giza 179 and Hybridl rice. Some physical properties for paddy are discussed briefly. The average grain length, width and thickness were measured. The surface area and the volume were determined. The values of particle density, bulk density, and porosity were measured. The equivalent diameter and the weight of 1000 grains were also measured. The kernels sphericity was calculated. The Aspect ratio which is used as an indicator of a tendency toward an oblong shape was founded.

\section{INTRODUCTION}

The knowledge of the physical properties of the agricultural products is of a fundamental importance during the harvesting of

grains, transporting, design and dimensioning of correct storage procedure, manufacturing and operating different equipment used in post harvesting main processing operations of these products.

One of the most important cereals cultivated worldwide is rice (Oryza sativa L.), constituting the basic food for a large number of human beings, sustaining two-thirds of the world population (Zhout et al., 2002). For rice grain, rice milling is the process of applying load to the kernels in order to remove the bran layers and germ (Lu and Siebenmorgen, 1995). The marketing values of rice as an agricultural product depend on its physical qualities after the harvesting. The percentage of whole grain is the most important parameter for the rice processing industry (Marchezan, 1991).

*Rice Technology Training Center, Field Crops Research Institute, A.R.C., Alexandria, Egypt. 
Liu et al., (2009) investigated the physical properties (length, width, thickness, aspect ratio, equivalent diameter, sphericity, surface area, volume, bulk density, true density, porosity, thousand-seed weight and degree of milling) of brown rice during milling process.

During rice milling, kernels are exposed to different compressive, bending, shear and frictional forces, and breakage can consequently occur (Shitanda et al., 2002).

The machinery and operations when improperly designed may generate rice kernel cracking and breakage and consequently a low marketing price. So, the physical properties of rice, which are important in the design and selection of storage structures and storage and processing equipment, depend on grain moisture content. Therefore, the determination and consideration of properties such as bulk density, true density have an important role (Mohsenin 1980), (Molenda et al., 2002), (Kashaninejad et al., 2006).

The principal axial dimensions of rice seeds are useful in selecting sieve separators and in calculating power during the rice milling process. The information related to porosity and specific gravity, within other physical characteristics of the agricultural products, are of paramount importance for studies involving heat and mass transfer and air movement through the bulk grain.

In addition, together with moisture content, volume, specific gravity and porosity are the basic parameters for studying the drying and storage of agricultural products and to preview the quality loss of the material until its marketing time.

Cereal-grain kernel densities have been of interest in breakage susceptibility and hardness studies (Chang, 1988). The objective of this study was to determine some important physical properties of the variety of rice typically cultivated in Egypt, These varieties are Egyptian jasmine (long grain), Sakha 106 and Giza 179 (short grain), and Hybrid1 (medium grain).

\section{MATERIALS AND METHODS}

This work was carried out in the laboratories of Rice Technology Training Center (RTTC), Alexandria, Field Crops Research Institute, Cairo, Egypt. 


\section{Sample Preparation}

Four paddy rice varieties of the most spreading in Egypt were selected, Sakha 106 and Giza 179 as short grain varieties, Jasmine local aromatic as a long grain variety, and Hybrid1 rice as a medium grain variety. Amounts of 10 kilograms of each paddy rice variety were obtained of the 2013 crop from the experimental farm of Rice Research Training Center (RRTC), Sakha, Kafer-Elsheikh governorate.

Rice paddy samples were mechanically cleaned to remove foreign materials such as straw, soil particles, mud balls and weed seeds according to the different shape, size and specific weight. Cleaning was done by electric apparatus; namely Cater-Day Dockage Tester model (TGR) which consists of four oscillating and replicable sieves. Complete processing was done after three pass, then sorted by testing thickness grader model (TWS).

The paddy sample initial moisture content was determined by the oven method (Tabatabaeefar 2003).

The physical properties of paddy rice, which are important in the design, selection of storage structures, storage and processing equipment, depend on grain moisture content. Therefore, the determination and consideration of properties such as grains dimensions, grain volume, equivalent diameter, sphericity, and weight of 1000 grains, bulk density, and true density of grain have important role (Mohsenin, 1980; Molenda et al., 2002 and Kashaninejad et al., 2006). After the determination of the dimensions, all other measurements, which followed, were replicated five times concerning moisture content, and the averages were calculated. The grain or true density was determined using the toluene displacement method (Singh and Goswami, 1996). The bulk density was determined with a weight per hectoliter tester which was calibrated in $\mathrm{kg}$ per hectoliter (Deshpande and Ojha 1993; Sharma et al., 1985; Suthar and Das 1996 and Jain and Bal 1997).

\section{Size and shape}

The dimensions of each paddy variety samples were determined in term of length (L), width (W), and thickness (T) measured using the grain shape tester Satake model MK -100.The equivalent diameter $\left(\mathrm{D}_{p}\right)$ considering a prelate spheroid shape for a rice grain, was calculated 
through the following expression (Mohsenin, 1986; Jain and Bal, 1997; Reddy and Chakraverty, 2004; Soliman and Yehia 2012; Mir et al 2013):

$$
\mathrm{D}_{P}=\left[4 \mathrm{~L}\left\{\frac{\mathrm{w}+\mathrm{T}}{4}\right\}^{2}\right]^{1 / 3}
$$

Where: $\left(\mathrm{D}_{p}\right)$ is the equivalent diameter in $\mathrm{mm}$ and $(\mathrm{L}),(\mathrm{W})$ and (T) is are length, width and thickness of the grain in $\mathrm{mm}$, respectively.

The arithmetic mean diameter $\left(\mathrm{D}_{\mathrm{a}}\right)$ of the grain was calculated by using the following relationships (Dursun and Dursun, 2005):

$$
\mathrm{D}_{a}=(\mathrm{L}+\mathrm{W}+\mathrm{T}) / 3
$$

According to (Mohsenin, 1986; Soliman N.S. and M. Yehia, 2012 and Mir et al., 2013) the degree of sphericity, $(\Phi)$ can be expressed as follows:

$$
\Phi=\frac{(\mathrm{L} \mathrm{W} \mathrm{T})^{1 / \mathrm{s}}}{\mathrm{L}}
$$

Where $(\mathrm{L})$ is the grain length, $(\mathrm{W})$ the grain width and $(\mathrm{T})$ is the grain thickness.

The geometric mean diameter, $\left(\mathrm{D}_{g}\right)$ is given by (Sreenarayanan et al., 1985; Sharma et al., 1985; Dursun and Dursun, 2005; Jouki and Khazaei, 2012 and Prashant and Prasad, 2012).

$$
\begin{aligned}
& \mathrm{D}_{g}=(\mathrm{LWT})^{1 / 3} \\
& \Phi=\mathrm{D}_{g} / \mathrm{L}
\end{aligned}
$$

The grain surface area (S) was evaluated using (Jain and Bal, 1997; Sharma et al., 1985; Sreenarayanan et al., 1985; and Soliman and Yehia, 2012).

$$
\mathrm{S}=\frac{\pi B L^{2}}{2 L-B}
$$

$$
\text { Where } \mathrm{B}=(\mathrm{WT})^{0.5}
$$

The aspect ratio $\left(\mathrm{R}_{a}\right)$ was determined by using the following formulae (Varnamkhasti et al., 2008; Nimkar and Chattopadhyay, 2001; Dabbaghi 
PROCESS ENGINEERING

et al., 2013 and Mir et al. 2013).

$$
\mathrm{R}_{a}=\mathrm{W} / \mathrm{L}
$$

Jain and Bal (1997) have stated grain volume (V, $\mathrm{mm}^{3}$ ); (Mir et al., 2013; Jouki and Khazaei, 2012; and Soliman and Yehia, 2012) by using equation as following:

$$
\mathrm{V}=0.25\left\{(\pi / 6) \times \mathrm{L}(\mathrm{W}+\mathrm{T})^{2}\right.
$$

True density $\left(\mathrm{P}_{g}\right)$ was measured by using Sand displacement method (Rahman, 1995). The bulk density $\left(\mathrm{P}_{b}\right)$ was determined using SATAKE apparatus (MK-50A)

The Porosity $(\varepsilon)$ was computed by the following equations according to (Mohsenin, 1970; Thompson and Isaacs, 1967; Jouki and Khazaei, 2012; Jain and Bal, 1997; Mir et al., 2013; Prashant and Prasad, 2012; Sacilik et $a l ., 2003$ and Dabbaghi et al., 2013) the porosity, (ع), is given by:

$$
\varepsilon=\left(\mathrm{P}_{g}-\mathrm{P}_{b}\right) / \mathrm{P}_{g} \times 100
$$

Where $\left(\mathrm{P}_{b}\right)$ is the bulk density and $\left(\mathrm{P}_{g}\right)$ is the true density.

The thousand kernel weight was determined by randomly selecting one thousand grains from paddy rice samples and weighed (Varnamkhasti et al., 2008).

In order to determine the mean weight of 1000 grains, five samples of 1000 grains were randomly selected from each variety and each product using grain counter KY-130. Each sample was weighted using an electronic balance model sartorial (A13VA) with an accuracy of 0.01 grams.

\section{RESULTS AND DISCUSSION}

The results of measured physical characteristics of the four selected rice varieties of Egyptian Jasmine local aromatic as long grains, Sakha 106 and Giza 179 as short grain and Hybrid1 as medium grain are presented in table (1): 
Table (1): Average result of the physical characteristics of rice grains at $14 \%$ $\pm 0.24 \%$ moisture content

\begin{tabular}{|l|c|c|c|c|}
\hline $\begin{array}{c}\text { Average rice grains } \\
\text { physical } \\
\text { characteristics }\end{array}$ & $\begin{array}{c}\text { Egyptian } \\
\text { jasmine }\end{array}$ & $\begin{array}{c}\text { Sakha } \\
106\end{array}$ & $\begin{array}{c}\text { Giza } \\
179\end{array}$ & Hybrid1 \\
\hline $\begin{array}{l}\text { Mean Length of } 300 \\
\text { replicates, }(\mathrm{L}) \mathrm{mm}\end{array}$ & 9.939 & 7.587 & 7.836 & 8.391 \\
\hline $\begin{array}{l}\text { Mean Width of } 300 \\
\text { replicates, }(\mathrm{W}) \mathrm{mm}\end{array}$ & 2.575 & 3.427 & 3.286 & 3.224 \\
\hline $\begin{array}{l}\text { Mean Thickness of } \\
\text { 300 replicates, }(\mathrm{T}) \\
\text { mm }\end{array}$ & 1.789 & 2.325 & 2.160 & 2.199 \\
\hline Aspect Ratio, $\left(\mathrm{R}_{a}\right)$ & 0.259 & 0.451 & 0.419 & 0.384 \\
\hline $\begin{array}{l}\text { Mean Arithmetic } \\
\text { diameter, }\left(\mathrm{D}_{a}\right), \mathrm{mm}\end{array}$ & 4.767 & 4.446 & 4.427 & 4.604 \\
\hline $\begin{array}{l}\text { Mean Geometric } \\
\text { diameter, }\left(\mathrm{D}_{g}\right), \mathrm{mm}\end{array}$ & 3.577 & 3.924 & 3.817 & 3.903 \\
\hline $\begin{array}{l}\text { Mean Equivalent } \\
\text { diameter, }\left(\mathrm{D}_{p}\right), \mathrm{mm}\end{array}$ & 3.617 & 3.973 & 3.873 & 3.951 \\
\hline Mean Sphericity, $(\Phi)$ & 0.359 & 0.517 & 0.487 & 0.465 \\
\hline $\begin{array}{l}\text { Mean Surface area, } \\
(\mathrm{S}), \mathrm{mm}{ }^{2}\end{array}$ & 37.550 & 41.304 & 39.496 & 41.693 \\
\hline $\begin{array}{l}\text { Mean Grain volume, } \\
(\mathrm{V}), \mathrm{mm}^{3}\end{array}$ & 24.770 & 32.837 & 30.415 & 32.286 \\
\hline $\begin{array}{l}\text { Mean Bulk density of } \\
5 \text { replicates, }\left(\mathrm{P}_{g}\right) \mathrm{kg} / \mathrm{m}^{3}\end{array}$ & 489.154 & 542.335 & 561.809 & 588.094 \\
\hline $\begin{array}{l}\text { Mean True density of } 5 \\
\text { replicates, }\left(\mathrm{P}_{b}\right) \mathrm{kg} / \mathrm{m}^{3}\end{array}$ & 1194.320 & 1148.720 & 1189.968 & 1245.542 \\
\hline Mean Porosity, \% & 59.043 & 52.787 & 30.182 & 29.630 \\
\hline $\begin{array}{l}\text { Mean 1000 weight } \\
\left(\mathrm{W}_{1000}\right) \text { of 5 replicates,g. }\end{array}$ & 22.300 & 26.080 & 24.040 & 25.520 \\
\hline
\end{tabular}

\section{1-Dimensions:}

The average of the three principal dimensions to rice grains (Egyptian Jasmine local aromatic as a long grain variety) length, width and 
thickness were found to be $9.939,2.575$ and $1.789 \mathrm{~mm}$, respectively. Corresponding value for the average of Sakha 106 (as a short grain variety) were 7.587, 3.427 and $2.325 \mathrm{~mm}$., value for the average of Giza 179 (as a short grain variety) were 7.836, 3.286 and $2.160 \mathrm{~mm}$, respectively, and value for the average of Hybrid1 (as a medium grain variety) were found to be $8.391,3.224$ and $2.199 \mathrm{~mm}$. respectively.

Analysis of variance of some important physical properties of the paddy rice was applied and the results indicated that there were highly significant difference $(\mathrm{P}<0.01)$ between the varieties for all of the measured physical properties. The importance of dimensional characteristics of paddy rice in determining aperture sizes and other adjusted parameters of machine operations have been discussed by Mohsenin (1986) and highlighted lately by Omobuwajo et al. (1999). The means for physical properties of the four varieties of Egyptian Jasmine, Sakha 106, Giza 179 and Hybrid1 are given in table (1), it can be seen that the average value of length for paddy rice of Egyptian Jasmine variety $(9.94 \mathrm{~mm})$ was to be more than Hybrid1 $(8.39 \mathrm{~mm})$, Giza 179 (7.84 mm) and Sakha $106(7.59 \mathrm{~mm})$; whereas the mean values of width and thickness for Sakha $106(3.43,2.33)$ was higher than those of Giza 179 (3.29, 2.16), Hybrid1 (3.23, 2.20) and Egyptian Jasmine (2.58, 1.79 $\mathrm{mm})$.

Equivalent mean diameters $\left(\mathrm{D}_{p}\right)$, arithmetic mean diameter $\left(\mathrm{D}_{a}\right)$ and geometric mean diameter $\left(\mathrm{D}_{g}\right)$ confirmed the interest in the rice-milling industry about the differences in the dimensions of Rice grains varieties. The values of equivalent diameter $\left(\mathrm{D}_{p}\right)$, arithmetic mean diameter $\left(\mathrm{D}_{a}\right)$ and geometric mean diameter $\left(\mathrm{D}_{g}\right)$ were obtained mathematically using equation (1), (2) and (4).

The average values of equivalent diameter, arithmetic mean diameter and geometric mean diameter for Sakha 106 (3.973, 4.446, and $3.924 \mathrm{~mm}$ ) were significantly higher than those of Hybrid1 (3.951, 4.604, and 3.903 $\mathrm{mm})$, Egyptian jasmine (3.617, 4.767, and 3.577) and Giza 179 (3.873, 4.427 , and $3.817 \mathrm{~mm}$ ). This can affect the design parameters of the seeder machines in mechanized rice planting method. 


\section{2-Aspect Ratio $\left(\mathbf{R}_{\mathbf{a}}\right)$ :}

The aspect ratios $\left(\mathrm{R}_{\mathrm{a}}\right)$ were calculated for each variety as an indicator of a tendency toward an oblong shape Fig. (1, 2, 3 and 4). Sakha 106 variety was 0.451 , Giza 179 0.419, Hybrid 1 was 0.384 and a corresponding value of Egyptian jasmine local aromatic variety was 0.259.

The relationship between kernel mass and aspect ratio (W / L) was obtained by statistical regression analysis, which produced the pest fit third degree polynomial equation with a high coefficient of determination for each of sakha 106, Hybrid1 rice, Giza 179 and Jasmine Egyptian rice varieties respectively, as shown in figures 1, 2, 3 and 4 .

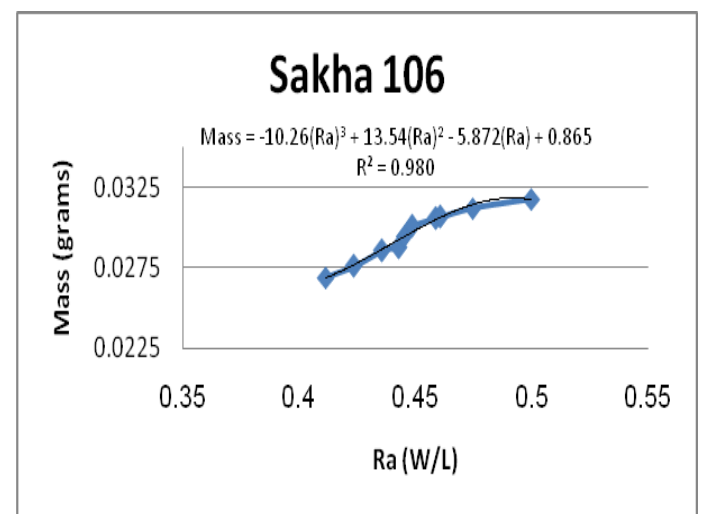

Figure (1) Relationship between kernel mass and aspect ratio (W/L) for Sakha 106 paddy rice variety.

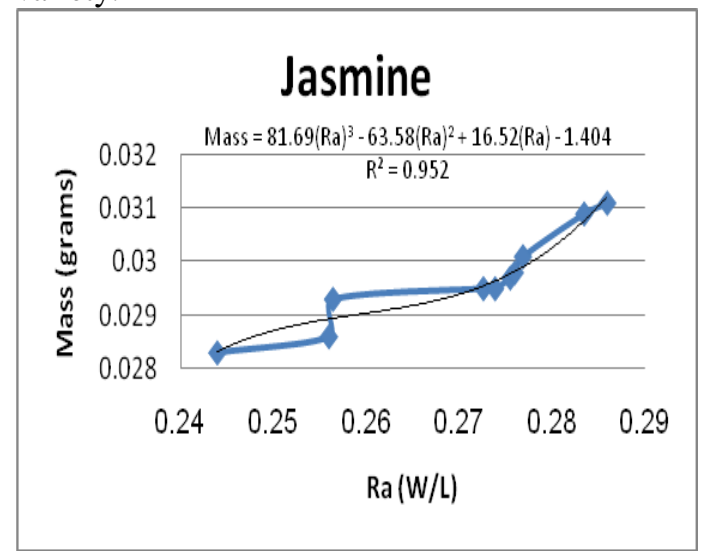

Figure (3) Relationship between kernel mass and aspect ratio (W/L) for Jasmine Egyptian paddy rice variety.

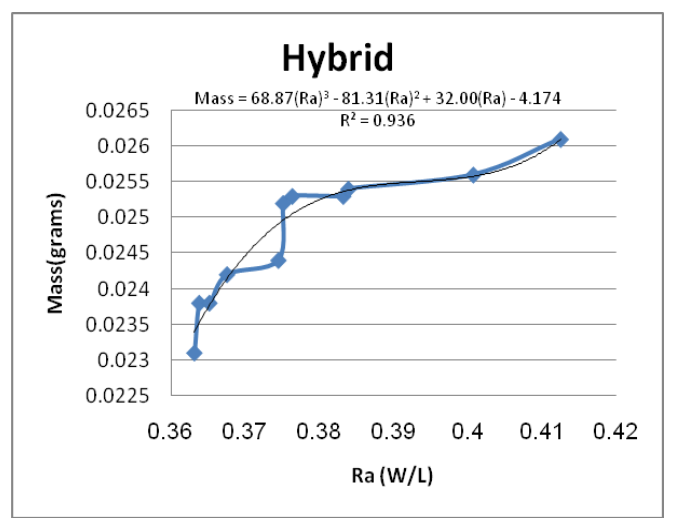

Figure (2) Relationship between kernel mass and aspect ratio (W/L) for Hybrid1 paddy rice variety.

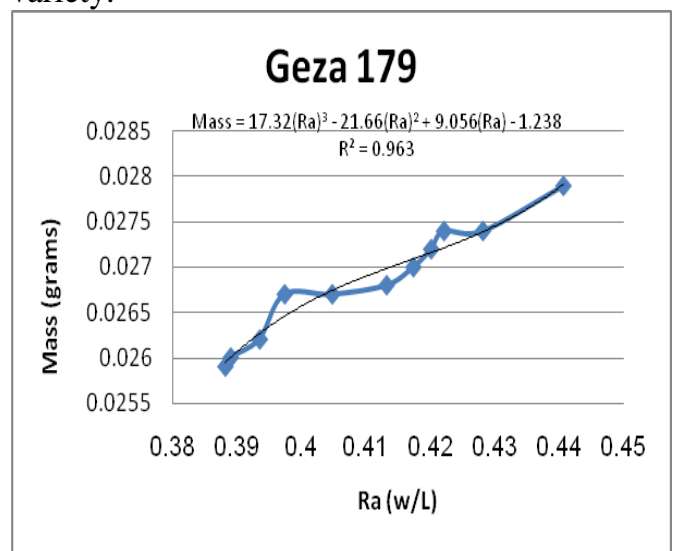

Figure (4) Relationship between kernel mass and aspect ratio (W/L) for Giza 179 paddy rice variety. 


\section{3-Sphericity $(\Phi)$ :}

The sphericity $(\Phi)$ of Sakha 106 was 0.517 , Egyptian Jasmine was 0.359, Giza 179 was 0.487 and Hybrid1 was 0.465 which indicated that the shape of the grains makes it difficult to roll on the surface. These values should give a sign to the rice industry producers on the sensitivity of handling with these differences.

\section{4- Volume $(V)$ and Surface $\operatorname{area}(S)$ :}

The volumes of paddy grains of the four varieties were estimated using toluene displacement technique and verified by equation (9). The volume of a single grain of Sakha 106 was $32.837 \mathrm{~mm}^{3}$, Egyptian jasmine 24.770 $\mathrm{mm}^{3}$, Giza $17930.415 \mathrm{~mm}^{3}$ and the volume of Hybrid1 variety was $32,286 \mathrm{~mm}^{3}$. The surface area of paddy grains were evaluated by equation (6), and were 41.304 for Sakha 106 variety to $37.550 \mathrm{~mm}^{2}$ for Jasmine local aromatic variety, Giza $17939.496 \mathrm{~mm}^{2}$ and Hybrid1 variety was $41.693 \mathrm{~mm}^{2}$. The values of surface areas give rice industry producer a good indicator for the highest rice husk percentage of long variety than short varieties. This affects all thermal treatments, heat and mass transfer through drying process and plays an important role in parboiling rice processing, for determining the required time of stepping and drying stage.

\section{5- Bulk, True Density and Porosity:}

The true density $\left(\mathrm{P}_{g}\right)$, bulk density $\left(\mathrm{P}_{b}\right)$ and porosity $(\varepsilon)$ were determined for each variety of rice grains. For Jasmine variety, they were 1194.320 $\mathrm{kg} / \mathrm{m}^{3}, 489.154 \mathrm{~kg} / \mathrm{m}^{3}$ and $59.043 \mathrm{~kg} / \mathrm{m}^{3}$, Sakha 106 were 1148.720 $\mathrm{kg} / \mathrm{m}^{3}, 542.335 \mathrm{~kg} / \mathrm{m}^{3}$ and $52.787 \mathrm{~kg} / \mathrm{m}^{3}$, Giza 179 were $1189.968 \mathrm{~kg} / \mathrm{m}^{3}$, $561.809 \mathrm{~kg} / \mathrm{m}^{3}$, and $30.182 \mathrm{~kg} / \mathrm{m}^{3}$ and Hybrid1 were $1245.542 \mathrm{~kg} / \mathrm{m}^{3}$, $588.094 \mathrm{~kg} / \mathrm{m}^{3}$, and $29.630 \mathrm{~kg} / \mathrm{m}^{3}$, respectively. The bulk density and the porosity, for each variety differ significantly, but the particle density values, practically did not present significant differences among the varieties. This characteristic can be used in air separation and cleaning processes for grains since lighter fractions will float. These values can help in the design of storage, warehouse, handling and transport operations. 


\section{6- Weight of one thousand grains (W 1000):}

The weight of one thousand grains is a useful parameter to "milling quality" in measuring the relative amount of quality and full grain and the amount of immature in lot of paddy kernels, also good indication of paddy rice prices. The measurements of weight of one thousand paddy rice grains of different varieties under study were conducted, and the weight of 1000 paddy grains for sakha 106 variety was 26.080 g, Paddy Jasmine was $22.300 \mathrm{~g}$, Giza 179 was $24.040 \mathrm{~g}$ and Hybrid1 was $25.520 \mathrm{~g}$. Increase of moisture content increased weight of one thousand grains and this is in agreement with Korayem and Soliman, (1983) and Kibar (2010). So, it is important to refer to the best moisture content when deal with rice on the industry level.

\section{CONCLUSION}

This study concludes the information on physical properties of the four selected paddy rice varieties Egyptian Jasmine local aromatic as long grains, Sakha106 as a short grains Giza 179 as short grain and Hybrid1 rice grain, which can be useful for designing equipment used for paddy processing. According to these values, rice markers adjust machines which give them productivity of whole grains and higher quality.

\section{REFERENCES}

Chang, C.S., 1988. Porosity and density of grain kernels.Cereal Chemistry, 65(1): 13-15.

Dabbaghi, A., J. Massah and M. R. Alizdeh, 2013. Physical properties of pregerminated paddy seeds of different varieties. Technical Journal of Engineering and Applied Sciences, 306-312

Deshpande, S.D. and T.P. Ojha, 1993. Physical properties of soybean. Journal of Agricultural Engineering Research 56:pp. 89-98.

Dursun, E., and I. Dursun, 2005. Some physical properties of caper seeds.Biosystems Engineering, 92(2): 237-245.

Jain, R.K. and S. Bal, 1997. Properties of pearl millet, Journal of Agricultural Engineering Research, 66: 85-91. 
Jouki, M. and N. Khazaie, 2012. Some physical properties of rice seed (Oryza Sativa). Research Journal of Applied Sciecnces, Engineering and Technology, 4(13): 1846-1849.

Kashaninejad, M.A., A. Mortazavi, A. Safekordi and L.G. Tabil, 2006. Some Physical Properties of Pistachio (Pistacia vera L.) nut and its kernel. Journal of Food Engineering, 72(1): 30-38.

KIBAR, H., T. Öztürk and B. ESEN, 2010. The effect of moisture content on physical and Mechanical properties of rice (Oryza sativa L.). Spanish Journal of Agricultural Research, v. 8, n. 3, p. 741-749.

Korayem, A.Y. and N.S. Soliman, 1983. Effect of moisture content of rough rice on its physical properties. Agri. Sci. \& Dev. Res. 5: 103-117.

Liu, K., X. Cao, Q. Bai, H. Wen and Z. Gu, 2009. Relationships between physical properties of brown rice and degree of milling and loss of selenium. Journal of Food Engineering, 94, 69-74.

Lu, T. and J. Siebenmorgen, 1995. Correlation of head rice yield to selected physical and mechanical properties of rice kernels. Transactions of the ASAE, 38, 889-894.

Marchezan, E., 1991. Grãos inteiros em arroz (Whole rice kernels in rice) Lavoura Arrozeira 44: 3-8 Porto Alegre, Brazil.

Mir, S.A., S.J.D. Bosco and K. Sunooj, 2013. Evaluation of physical properties of rice cultivars grown in the temperate region of India. International Food Research Journal, 20(4): 1521-1527.

Mohsenin, N.N., 1970. Physical properties of plant and animal material, Gordon and Breach, New York.

Mohsenin, N.N., 1980. Physical Properties of Plant and Animal materials.New York: Gorden and Breach.

Mohsenin, N.N., 1986. Physical properties of plant and animal Materials, $2^{\text {nd }}$ edition. Gordon and Breach Science Publishers, New York.

Molenda, M., M.D. Montross, J. Horabik and I.J. Ross, 2002. Mechanical Properties of corn and soybean meal. Tras. ASAE, 45(6): 1929-1936. 
Nimkar, P.M. and P.K. Chattopadhyay, 2001. Some physical properties of green gram. J. Agric. Eng. Res., 80 (2): 183-189.

Omobuwajo, T.O., E.A. Akanda and L.A. Sanni, 1999. Selected physical, mechanical and aerodynamic properties of African breadfruit (Treculla Africana) seeds. J. Food Eng., 40: 241-244.

Prashant, N. Ghadge and Prasad K. 2012. Some physical properties of rice kernels: variety PR-106. J. Food Process Technol. Vol. 3: 3-5.

Rahman, M.S., 1995. Handbook of food properties. CRC Press. Boca Raton, FL.

Reddy, B.S. and A. Chakaraverty, 2004. Physical properties of raw and parboiled paddy. Biosys. Eng., 88 (4): 461-466.

Sacilik, k., R. Ozturk and R. Keskin, 2003. Some physical properties of hemp seed. Biosys. Eng., 86 (2): 191-198.

Sharma, S. K., K. Dubey and C.K. Teckchandani, 1985. Engineering properties of black gram, soybean and green gram. Proceedings of Indian Society of Agricultural Engineering, 3: 181-185.

Shitanda, D., Y. Nishiyama and S. Koide, 2002. Compressive strength properties of rough rice considering variation of contact area. Journal of Food Engineering, 53: 53-58.

Singh, K.K., and T.K. Goswami, 1996. Physical properties of cumin seed. Journal of Agricultural Engineering Research, 64: 93-98.

Soliman, N.S. and M.E. Yehia 2012. Rice characteristics effect on processing. Misr Journal of Agricultural Engineering, 29(1): 273-288.

Sreenarayanan, V.V., V. Subramanian and R. Visvanathan, 1985. Physical and thermal properties of soyabean. Proceedings of Indian Society of Agricultural Engineers, 3: 161-169.

Suthar, S.H., and S.K. Das, 1996. Some physical properties ofkaringda seeds. Journal of Agricultural Engineering Research, 65: 15-22.

Tabatabaeefar, A., 2003. Moisture-dependent physical properties of wheat. International Agrophysics, 17: 207-211. 
Thompson, R.A. and G.W. Isaacs, 1967. Porosity determination of grains and seeds with air comparison pycnometer. Transactions of ASAE, 10: 693-696.

Varnamkhasti, M.G., H. Mobli, A. Jafari, A.R. Keyhani, M.H. Soltanabadi, S. Rafiee, and K. Kheiralipour, 2008. Some physical properties of rough rice (Oryza Sativa L.) grain. Journal of Cereal Science, 47: 496501.

Zhout, Z., K. Robards, S. Heliwell and C. Blanchard 2002. Ageing of stored rice: changes in chemical and physical attributes. Journal of Cereal Science 35, pp. 65-78.

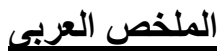

\section{الخصائص الطبيعية لأصناف جديدة من الارز الثعير المصرى}

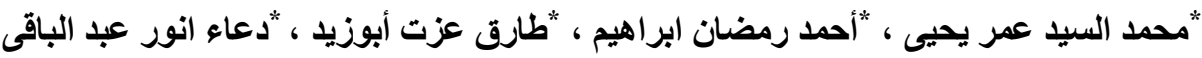

تعتبر الخصائص الطبيعية للأرز الشعير ذات أهمية كبيرة فى عمليات تجفيف وصناعة الأرز

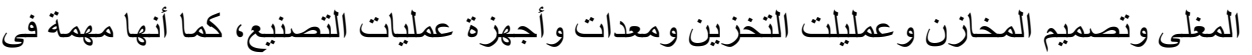

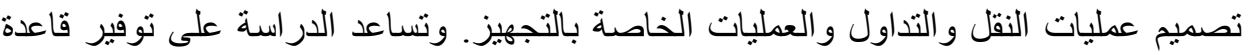

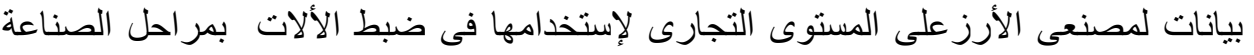

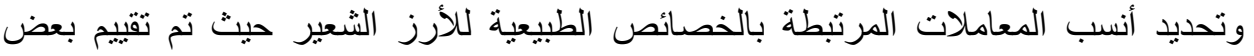

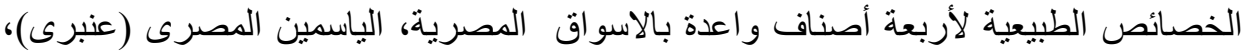

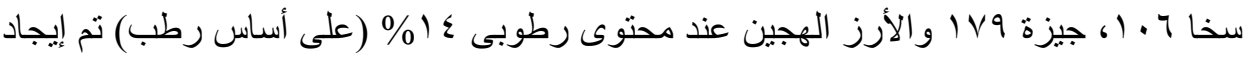

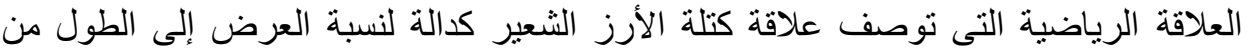

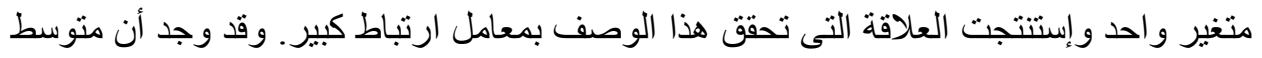

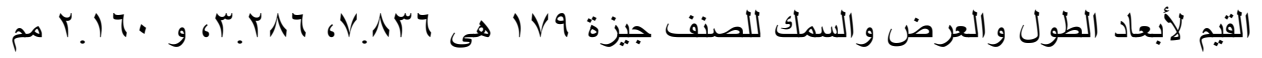

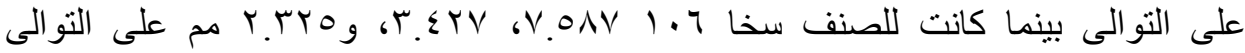

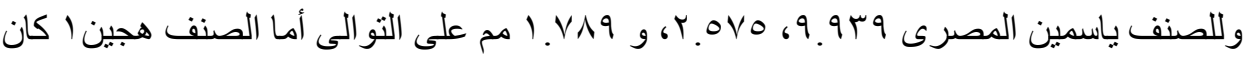

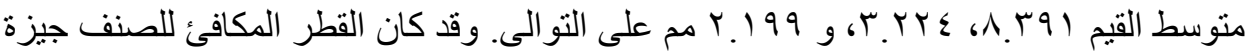

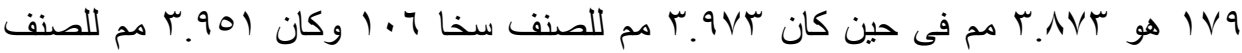
هجين ا بينما كان VI V.T V للصنف ياسمين المصرى. وتم تقدير كروية الحبوب و المساحة

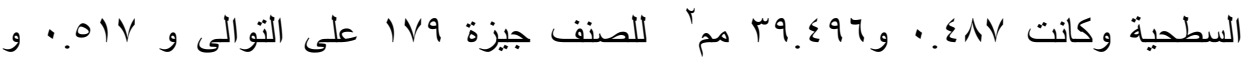

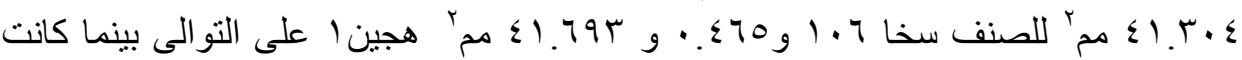

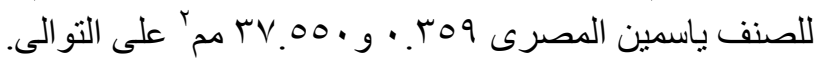

*مركز تدريب تكنولوجيا الارز بالاسكندريةـ معهد بحوث المحاصيل الحقلية ـ مركز البحوث الزراعية 


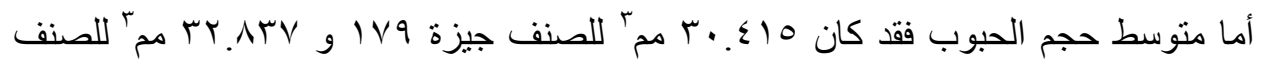

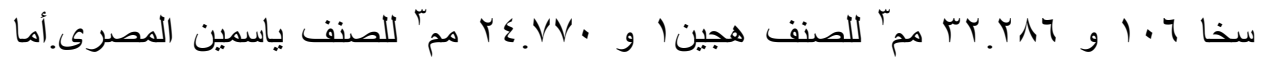

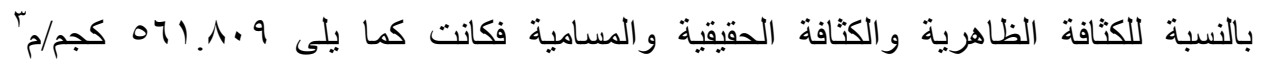

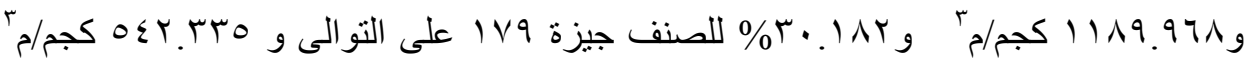

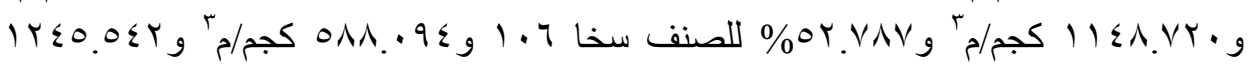

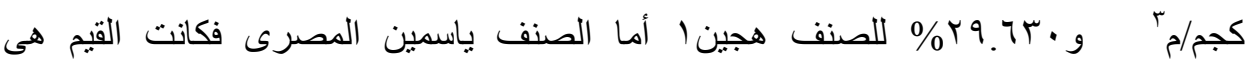

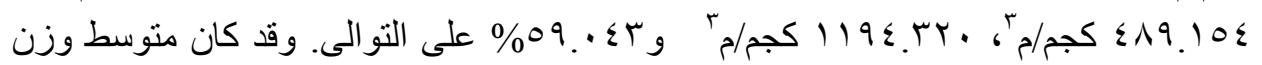

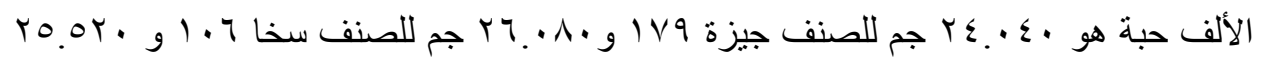

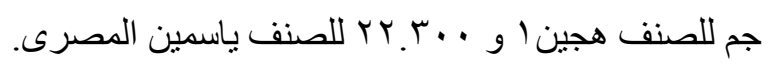

